Contraloría General De la República

D01.10.22199/507189753.2005.0001.00010

\title{
DIVISIÓN JURÍDICA
}

\author{
REF: $\quad N^{\circ} 22052 / 03$ \\ JPM10267/04
}

SOBRE JURIDICIDAD DE ACTOS ADMINISTRATIVOS QUE DECLARAN SECRETOS O RESERVADOS DOCUMENTOS Y ANTECEDENTES DE LOS ÓRGANOS DE LA ADMINISTRACIÓN DEL ESTADO.

SANTIAGO, 04. OCT 2004. 049883

Se han dirigido a esta Contraloría General don Patricio Herman y don Antonio García, en representación, según indican, de las organizaciones "Defendamos la Ciudad" y "Cívica, Derechos Ciudadanos", respectivamente, don Moisés Sánchez y don Edgardo Condeza, solicitando un pronunciamiento relativo a la legalidad de las letras b), del $\mathrm{N}^{\circ} 2, \mathrm{y}$ d), h), i), 1) y m), del $\mathrm{N}^{\circ} 4$ de la resolución exenta $\mathrm{N}^{\circ} 388$ de 2003 , de la Comisión Nacional del Medio Ambiente, mediante la cual ese servicio determinó actos, documentos y antecedentes afectos a secreto 0 reserva.

Ello, por cuanto contravendrían lo dispuesto en la ley $\mathrm{N}^{\circ} 19.300$, sobre Bases Generales del Medio Ambiente; en los decretos Nº. 93 y 94 de 1995, del Ministerio Secretaría General de la Presidencia de la República -que aprobaron respectivamente el Reglamento para la Dictación de Normas de Calidad Ambiental y de Emisión y el Reglamento que fija el Procedimiento y Etapas para establecer Planes de Prevención y de Descontaminación-; en las leyes $\mathrm{N}^{\circ}$ s. 18.575, Orgánica Constitucional de Bases Generales de la Administración del Estado, y 19.880, sobre Bases de los Procedimientos Administrativos que rigen los actos de los Órganos de la Administración del Estado, y en el decreto $\mathrm{N}^{\circ} 26$ de 2001, del Ministerio Secretaría General de la Presidencia de la República, Reglamento sobre el secreto o reserva de los actos y documentos de la Administración del Estado.

Concluyen su presentación solicitando que la Contraloría General declare la ilegalidad de otros 49 actos administrativos que individualizan, emitidos por diversas entidades de la Administración, que también establecen el secreto o reserva de ciertos documentos. 


\section{AL SEÑOR \\ MINISTRO SECRETARIO GENERAL DE LA PRESIDENCIA DE LA REPÚBLICA PRESENTE}

Requeridos para que informasen sobre el particular, la Subsecretaría del Ministerio Secretaría General de la Presidencia y la Comisión Nacional del Medio Ambiente han emitido conjuntamente el oficio ord. (DJ) $\mathrm{N}^{\circ} 1049$, suscrito el 19 de julio de 2004 , sosteniendo la legalidad de las resoluciones impugnadas.

\section{Cuestiones Previas}

En relación con la materia, debe tenerse presente que de conformidad con lo dispuesto en el inciso segundo del artículo 13 de la ley $\mathrm{N}^{\circ} 18.575$, la función pública debe ejercerse con transparencia, "de manera que permita y promueva el conocimiento de los procedimientos, contenidos y fundamentos de las decisiones que se adopten en ejercicio de ella",

El inciso tercero de la misma norma añade que son públicos "los actos administrativos de los órganos de la Administración del Estado y los documentos que les sirvan de sustento o complemento directo y esencial", y los incisos siguientes del indicado precepto regulan, en lo que interesa, la forma de acceder a la información, los casos en que no procede, y el derecho a oposición por terceros interesados.

En particular, el inciso final del mismo artículo 13 que se comenta previene que "uno o más reglamentos establecerán los casos de secreto o reserva de la documentación y antecedentes que obren en poder de los órganos de la Administración del Estado". En virtud de este precepto se dictó el decreto $\mathrm{N}^{\circ}$ 26, de 2001, del Ministerio Secretaría General de la Presidencia de la República, que contiene, como antes se expuso, el Reglamento sobre el secreto o reserva de los actos y documentos de la Administración del Estado.

Por su parte, la ley $\mathrm{N}^{\circ} 19.880$ reitera lo expuesto en la norma recién aludida, al establecer en su artículo $4^{\circ}$ que el procedimiento administrativo está sometido, entre otros, a los principios de transparencia y publicidad, y en su artículo 16 que "el procedimiento administrativo se realizará con transparencia, de manera que permita y promueva el conocimiento, contenidos y fundamentos de las decisiones que se adopten en él", por lo que, añade, "salvo las excepciones establecidas por la ley o el reglamento, son públicos los actos administrativos de los órganos de la Administración del Estado y los documentos que le sirvan de sustento o complemento directo o esencial". 
En este contexto, es necesario anotar que de conformidad con lo dispuesto en el artículo $6^{\circ}$ del ya individualizado decreto $\mathrm{N}^{\circ} 26$ de 2001, se exceptúan de la publicidad regulada en ese decreto "los actos administrativos, documentos y antecedentes declarados secretos o reservados de conformidad a las normas del presente reglamento, sin perjuicio de lo establecido en leyes o reglamentos especiales".

A su turno, el artículo $8^{\circ}$ añade que "solo podrán ser declarados como secretos o reservados los actos y documentos cuyo conocimiento o difusión pueda afectar el interés público o privado de los administrativos", de acuerdo con los criterios que la misma norma señala, correspondiéndole al respectivo jefe superior de servicio, mediante resolución fundada, "determinar los actos, documentos y antecedentes de la institución u órgano de la Administración del Estado que estarán afectos al secreto o reserva", según lo indica su artículo $9^{\circ}$.

De la normativa precedentemente citada es posible observar, entonces, que tal como lo ha destacado la jurisprudencia administrativa, los artículos 13 de la ley $\mathrm{N}^{\circ} 18.575$ y 16 de la ley $\mathrm{N}^{\circ} 19.880$ regulan especialmente la transparencia y publicidad de los actos administrativos -esto es, al tenor del artículo $3^{\circ}$ de la última ley citada, de las decisiones formales que emitan los órganos de la Administración del Estado en las cuales se contienen declaraciones de voluntad, realizadas en ejercicio de una potestad pública-, y la de los documentos que le sirvan de fundamento.

Por consiguiente, las resoluciones que dicten los jefes de servicio destinadas a declarar secretos o reservados determinados instrumentos, emitidas al amparo del artículo $9^{\circ}$ del decreto $\mathrm{N}^{\circ} 26$ de 2001, deben decir relación exclusivamente con actos administrativos y documentos que le sirvan de sustento o complemento directo y esencial, siendo improcedente que se refieran a antecedentes que no revistan ese carácter.

Por otra parte, de lo expuesto no se sigue que los antecedentes que no constituyan actos administrativos o documentos que les sirvan de sustento o complemento directo y esencial sean secretos o reservados, sino tan solo que ellos no pueden ser solicitados haciendo uso del procedimiento previsto en el artículo 13 de la ley $\mathrm{N}^{\circ} 18.575$.

En efecto, tal como to ha precisado la jurisprudencia administrativa contenida en los dictámenes $\mathrm{N}^{\circ}$ s. 35.259 de 2000, y 4.228 de 2002, si bien la regulación del artículo 13 de la aludida ley $\mathrm{N}^{\circ} 18.575$ no ampara a los interesados en obtener copia de documentos que no constituyen actos administrativos ni le sirven. de fundamento, ello no significa que en virtud de esa disposición estos antecedentes sean secretos o reservados y no puedan o no deban darse a conocer a terceros interesados, toda vez que el principio de transparencia afecta a toda la gestión administrativa.

Por lo tanto, y tal como se señaló en el primero de dichos dictámenes, la Administración activa se encuentra obligada a entregar copia de 
un documento a un particular que lo requiera siempre que ese documento no se refiera a asuntos que revistan el carácter de reservados, y que la información contenida en el antecedente solicitado afecte directamente al particular o se vincule con situaciones fácticas concretas en que le corresponda intervenir.

De este modo, el examen de legalidad de las disposiciones cuestionadas de la resolución exenta $\mathrm{N}^{\circ} 388$ implica analizar si los documentos o antecedentes que ella declara como reservados son actos administrativos o documentos que le sirvan de fundamento, y si han podido ser excluidos del principio general de transparencia regulado en la ley $\mathrm{N}^{\circ} 18.575$, mediante un acto administrativo emitido en concordancia con el citado decreto $\mathrm{N}^{\circ} 26$ de 2001.

\section{ANÁlisis DE LAS IMPUgNACIONES A LA RESOLUCIÓN EXENTA N ${ }^{\circ}$ 388 DE 2003, DE LA COMISIÓN NACIONAL DEL MEdio AMBIENTE}

1. Letra b) del $\mathrm{N}^{\circ} 2$ de la resolución exenta $\mathrm{N}^{\circ} 388$ de 2003 , de la Comisión Nacional del Medio Ambiente

En primer término, los recurrentes objetan la legalidad de la letra b), del $\mathrm{N}^{\circ} 2$, de la resolución exenta $\mathrm{N}^{\circ} 388$ de 2003 , en virtud de la cual la Comisión Nacional del Medio Ambiente determinó que tiene el carácter de reservada "en razón de la debida protección de los intereses públicos", la "documentación relacionada con las demandas, recursos y/o reclamos, interpuestos ante los tribunales de Justicia, en contra del Servicio, así como los informes que este debe emitir por disposición de estos tribunales y todos los antecedentes que les sirven de sustento y/o complemento directo".

Los interesados manifiestan que esta norma va más allá de lo que permiten la ley y la letra a), $\mathrm{N}^{\circ} 6$, del artículo $8^{\circ}$ del decreto $\mathrm{N}^{\circ} 26$ de 2001 , conforme al cual la declaración de secreto o reserva basada en la protección de intereses públicos, procederá respecto de los actos y documentos "cuya comunicación o conocimiento perjudique el desarrollo de procedimientos jurisdiccionales o de actuaciones preliminares o preparativas de aquellos que la ley encomiende a organismos de la Administración".

Por su parte, la Subsecretaría y la Comisión informantes exponen que la reserva dispuesta por esta letra b) no se refiere a actos administrativos ni a documentos que sirvan de sustento directo y esencial a un acto administrativo en los términos previstos por la ley $\mathrm{N}^{\circ} 18.575$ y el reglamento respectivo, por lo que no tienen carácter público; que la reserva no se fundamenta en el $\mathrm{N}^{\circ} 6$ de la letra a) del decreto $\mathrm{N}^{\circ} 26$ de 2001, sino que en el $\mathrm{N}^{\circ} 8$ del mismo precepto -que permite la declaración de 
secreto o reserva basada en la protección de intereses públicos, respecto de documentos "cuyo conocimiento actual pueda impedir u obstaculizar gravemente el ejercicio de la acción administrativa del órgano administrativo requerido"-; que la reserva no afecta el derecho a reclamo previsto en el artículo 50 de la ley $\mathrm{N}^{\circ} 19.300$; y que la reserva solo rige para la señalada Comisión y no se extiende a los procesos y expedientes judiciales.

En relación con la materia, es necesario tener en cuenta que los documentos a que se refiere esta letra b) no constituyen actos administrativos decisión: les en los términos que prevén los artículos 13 de la ley $\mathrm{N}^{\circ} 18.575$ y 16 de la ley $\mathrm{N}^{\circ} 19.880$ y el decreto $\mathrm{N}^{\circ} 26$ de 2001 , del Ministerio Secretaría General de la Presidencia, ya que no contienen en sí mismos una resolución sobre alguna materia determinada, ni tampoco están destinados a servir de sustento o complemento directo y esencial a un acto de este tipo.

Así lo reconocen, por lo demás, la propia Comisión emisora del acto cuestionado y la Subsecretaría de Estado indicada, las cuales señalan que "los antecedentes a los que esta disposición confiere el carácter de reservados no constituyen actos administrativos ni documentos que sirvan de sustento directo o esencial a un acto administrativo", sino que "se trata de documentación, 'informes' que se emiten a los tribunales, y 'antecedentes' que sustenten dichos informes".

Por consiguiente, y de acuerdo con lo antes señalado, estos antecedentes no han podido ser declarados como reservados por la Comisión Nacional del Medio Ambiente al amparo de la normativa de que se trata, toda vez que no corresponden a aquellos regulados en el artículo 13 de la ley $\mathrm{N}^{\circ} 18.575$.

\section{Letra d) del $\mathrm{N}^{\circ} 4$ de la resolución exenta $\mathrm{N}^{\circ} 388$ de 2003, de la Comisión Nacional del Medio Ambiente}

Enseguida, los recurrentes impugnan la letra d) del $\mathrm{N}^{\circ} 4$ de la resolución exenta $\mathrm{N}^{\circ} 388$, a través de la cual la Comisión Nacional del Medio Ambiente estableció que, "en razón de la debida protección de los intereses privados", tiene el carácter de reservada "toda la información relativa a las remuneraciones del personal". En tal sentido, expresan que "la información de la remuneración de una persona no conlleva juicio de valor, y no es razonable pensar que afecte su vida privada".

A su vez, el oficio ord. (DJ) $N^{\circ} 1049$, suscrito el 19 de julio de 2004, afirma que la divulgación de las remuneraciones de una persona puede afectar su vida privada, la que está protegida por la ley $\mathrm{N}^{\circ} 19.628$, sobre protección de datos de carácter personal.

Al respecto, es posible observar que la información a que alude esta letra d) tampoco dice relación con actos administrativos ni con documen- 
tos que les sirvan de sustento o complemento directo y esencial, por lo que no corresponde que los instrumentos que declaran secreta o reservada cierta información al amparo de la normativa de que se trata se refieran a ellos.

3. Letras h) e i) del $\mathrm{N}^{\circ} 4$ de la resolución exenta $\mathrm{N}^{\circ} 388$ de 2003 , de la Comisión Nacional del Medio Ambiente

En tercer término, las letras h) e i) del $\mathrm{N}^{\circ} 4$ asignan, respectivamente, el carácter de reservados "en razón de la debida protección de los intereses privados", a los "documentos respaldatorios de las ofertas presentadas en procesos, de licitación o contratación, en tanto se encuentre pendiente su adjudicación, salvo las propuestas económicas, y aquellas que deban serlo según las Bases Administrativas respectivas" y a las "actas de comisiones evaluadoras en propuestas o licitaciones, en tanto se encuentre pendiente la adjudicación".

Los peticionarios afirman que estas letras no tienen respaldo normativo en el reglamento, debido a que los $\mathrm{N}^{\circ}$ s. 1 a 5 de la letra b) de su artículo $8^{\circ}$ se refieren a otro tipo de situaciones.

A su turno, la Subsecretaría del Ministerio Secretaría General de la Presidencia y la Comisión Nacional del Medio Ambiente exponen que estas letras se refieren a información protegida que no tiene carácter público, y que ellas no hacen sino recoger y reproducir un mandato legal y reglamentario general y disponer que al interior de la institución dichos antecedentes sean manejados con carácter reservado.

Sobre el particular, debe señalarse que los documentos comprendidos en las letras precedentemente transcritas no constituyen en sí actos administrativos, pero tal como lo ha sostenido la jurisprudencia administrativa contenida en el dictamen $\mathrm{N}^{\circ} 2.420$, de 2004, ellos sirven de antecedente para la dictación del decreto o resolución que adjudique la propuesta $y$, como tales, son documentos que pueden ser conocidos por quienes tengan interés en los mismos en los términos previstos en los artículos 13 de la ley $\mathrm{N}^{\circ} 18.575$ y 16 de la ley $\mathrm{N}^{\circ} 19.880$ y en el decreto $\mathrm{N}^{\circ} 26$ de 2001, del Ministerio Secretaría General de la Presidencia, esto es, una vez que se haya dictado el acto administrativo que adjudique la licitación respectiva, pues solo a partir de ese momento existirá un acto administrativo en los términos previstos por la legislación pertinente.

Así lo reconocen por lo demás la Subsecretaría y la Comisión emisora del acto impugnado, las que afirman que la reserva de la información a que aluden estas letras h) e i) opera solo mientras el acto definitivo no sea dictado, ya que "la protección está expresamente acotada en el tiempo 'en tanto se encuentre pendiente la adjudicación', es decir en tanto no se dicte el acto administrativo que contendrá la decisión formal y final del respectivo procedimiento". 
De este modo, si bien propiamente no corresponde incluir estas materias en la resolución objetada, los términos en que se consignan no afectan la regulación de que se trata.

\section{Letras 1) y m) del $\mathrm{N}^{\circ} 4$ de la resolución exenta $\mathrm{N}^{\circ} 388$ de 2003, de la Comisión Nacional del Medio Ambiente}

Los particulares y las organizaciones recurrentes sostienen que las letras l) y $\mathrm{m}$ ) no encuentran respaldo normativo en el reglamento, ya que los $\mathrm{N}^{\circ}$ s. 1 a 5 de la letra b) de su artículo $8^{\circ}$ no las contemplarían de ningún modo, y que ellas contravendrían expresamente lo dispuesto en los artículos $5^{\circ}$, inciso primero, y $8^{\circ}$, inciso primero, del Reglamento para la Dictación de Normas de Calidad Ambiental y de Emisión, y en los artículos $3^{\circ}$ y $5^{\circ}$ del Reglamento que fija el Procedimiento y Etapas para establecer Planes de Prevención y de Descontaminación.

A su vez, la Subsecretaría de Estado aludida y la Comisión emisora del acto administrativo objetado manifiestan que el secreto o reserva proviene no solo de las causales señaladas en el decreto $\mathrm{N}^{\circ} 26$ de 2001 , sino que también de aquellas establecidas en otras disposiciones reglamentarias, y que, en tal sentido, las letras cuestionadas tienen su fundamento tanto en la ley $\mathrm{N}^{\circ} 18.575$ como en los ya individualizados decretos $\mathrm{N}^{\circ}$ s. 93 y 94, ambos de 1995.

En relación con esta impugnación, corresponde tener en cuenta que la letra 1) del $\mathrm{N}^{\circ} 4$ de la resolución exenta que se analiza previene que "tienen carácter de reservados, en razón de la debida protección de los intereses privados" los "documentos acompañados a un expediente formado para la dictación de una norma de calidad o de emisión, respecto de los cuales el Director Ejecutivo, por resolución fundada, niegue el acceso a terceros, cuando así lo solicita el interesado o cuando así lo proponga el Presidente del Comité Operativo, conforme al artículo 8 del DS 93/95, del Ministerio Secretaría General de la Presidencia, Reglamento para la Dictación de Normas de Calidad Ambiental y de Emisión".

A su turno, la letra $\mathrm{m}$ ) asigna el mismo carácter de reservado a los "documentos acompañados por los titulares de las actividades responsables de la emisión de los contaminantes a un expediente formado para la dictación de un Plan de Prevención o Descontaminación respecto de los cuales el Director Ejecutivo, mediante resolución fundada, niegue el acceso a terceros cuando la ley así lo disponga, cuando lo solicite el interesado por razones fundadas o cuando así lo proponga el Presidente del Comité Operativo, conforme al artículo 5 del OS 94/95, del Ministerio Secretaría General de la Presidencia, Reglamento que fija el Procedimiento y Etapas para Establecer Planes de Prevención y Descontaminación". 
Asimismo, tal como ya se ha expuesto, el inciso final del artículo 13 de la ley $\mathrm{N}^{\circ} 18.575$ prevé que tanto la ley como el reglamento establezcan los casos de secreto o reserva de los actos administrativos y la documentación y antecedentes que obren en poder de los órganos de la Administración del Estado, mientras que el ya referido artículo $6^{\circ}$ del decreto $\mathrm{N}^{\circ} 26$ de 2001, previene que la excepción de la publicidad regulada en ese decreto de los actos administrativos, documentos y antecedentes declarados secretos o reservados de conformidad a las normas del mismo, debe entenderse "sin perjuicio de lo establecido en leyes o reglamentos especiales".

De esta manera, la propia ley orgánica constitucional recién citada permite la existencia de documentos y antecedentes sometidos a secreto o reserva tanto en virtud de lo prescrito en el Reglamento sobre secreto o reserva de los actos y documentos de la Administración, como de otros reglamentos específicos distintos de aquel.

Ahora bien, el artículo $8^{\circ}$ del Reglamento para la Dictación de Normas de Calidad Ambiental y de Emisión previene que el expediente a que da origen el proceso de dictación de normas de este tipo y su archivo son públicos, en los términos que allí se señalan. Con todo, agrega el inciso segundo de esta norma, en lo que resulta pertinente, que "El Director, mediante resolución fundada, podrá negar el acceso a terceros de los documentos acompañados cuando así lo solicite el interesado o cuando así lo proponga el presidente del Comité".

Como puede apreciarse, entonces, lo dispuesto en la letra 1) que ha sido objetada coincide en lo sustantivo con lo previsto en el artículo $8^{\circ}$ del decreto $\mathrm{N}^{\circ} 93$ de 1995.

Enseguida, y de manera similar a la recién descrita, el artículo $5^{\circ}$ del Reglamento que fija el Procedimiento y Etapas para establecer Planes de Prevención y de Descontaminación previene que la elaboración de estos planes "dará origen a un expediente, que contendrá las resoluciones que se dicten, la consultas evacuadas, las observaciones que se formulen, y todos los datos y documentos relativos a la elaboración" de los mismos. Añade la misma norma que "el expediente y su archivo serán públicos y se mantendrán en las oficinas de la Comisión, donde podrán ser consultados. Cualquier persona podrá pedir, a su costo, fotocopia de todas o algunas de las piezas".

No obstante lo anterior, el inciso quinto del mismo precepto previene, en lo que interesa, que el Director Ejecutivo de la Comisión, mediante resolución fundada, "podrá negar el acceso de terceros a los documentos acompañados por los titulares de las actividades responsables de la emisión de los contaminantes a que se refiere el plan, cuando la ley así lo disponga o cuando lo solicite el interesado por razones fundadas o cuando así lo proponga el presidente del Comité". 
De ello se deduce que la letra $\mathrm{m}$ ) del $\mathrm{N}^{\circ} 4$ de la resolución exenta en comento concuerda en lo sustantivo con lo previsto en el artículo $5^{\circ}$ del decreto $\mathrm{N}^{\circ}$ 94, de 1995.

Por este motivo, los literales que se analizan encuentran su fundamento en normas reglamentarias específicas, sin que extiendan la reserva a casos distintos de los regulados por dichos reglamentos, por lo que no se produce el efecto señalado por los peticionarios en orden a que la resolución exenta $\mathrm{N}^{\circ} 388$ haga más severa la reserva establecida sobre la materia.

Adicionalmente, es dable destacar que en las letras 1) y $\mathrm{m}$ ) se hace una expresa remisión a las normas reglamentarias respectivas, de lo que se deduce que la actuación de la Comisión Nacional del Medio Ambiente, llevada a cabo en virtud de esas letras no podría, en caso alguno, exceder lo dispuesto en los decretos $\mathrm{N}^{\circ}$ s. 93 y 94, del Ministerio Secretaria General de la Presidencia de la República, ya citados.

\section{ACTOS ADMINISTRATIVOS EMITIDOS POR DIVERSAS ENTIDADES DE LA ADMINISTRACIÓN}

Los peticionarios solicitan, por último, que se declare la ilegalidad de otros 49 actos administrativos emitidos por diversas reparticiones públicas, que también establecen el secreto o reserva de ciertos documentos invocando las normas del artículo 13 de la ley $\mathrm{N}^{\circ} 18.575$ y del decreto $\mathrm{N}^{\circ} 26$, de 2001, del Ministerio Secretaría General de la Presidencia de la República.

En esta materia, la Subsecretaría del Ministerio indicado y la Comisión Nacional del Medio Ambiente expresan que en virtud de la presunción de legalidad de los actos administrativos consagrada en el inciso final del artículo $3^{\circ}$ de la ley $\mathrm{N}^{\circ} 19.880$, sobre Bases de los Procedimientos Administrativos que rigen los actos de los Órganos de la Administración del Estado, debe desecharse la impugnación que los recurrentes plantean respecto de las 49 resoluciones a que se ha hecho mención, toda vez que ellos "se han limitado a señalar una especie de ilegalidad genérica, sin aducir ningún fundamento y sin identificar ninguna contravención o infracción normativa".

Ahora bien, realizado por esta Contraloría General un examen selectivo de algunas de las resoluciones que mencionan lo peticionarios, y de otras dictadas con el mismo fin, ha sido posible advertir que en ellas se regulan algunas materias similares a las que se han analizado precedentemente respecto de la resolución exenta $\mathrm{N}^{\circ} 388$, de 2003, de la Comisión Nacional del Medio Ambiente, particularmente en lo relativo a la inclusión de antecedentes que no revisten el carácter de actos administrativos o de documentos que les sirvan de sustento o complemento directo 
y esencial, y que, por tanto, no pueden ser declarados secretos o reservados al amparo del artículo 13 de la ley $\mathrm{N}^{\circ} 18.575$ y el Reglamento pertinente, de tal modo que este Órgano de Control no puede sino observar estas circunstancias.

Asimismo, dicho examen selectivo permite consignar que en numerosas resoluciones se excede la normativa a los efectos de la declaración de secreto o reserva en otros órdenes de materias.

Es así, verbigracia, que en lo que se refiere a los procesos disciplinarios respecto de funcionarios públicos, se establecen disposiciones sobre secreto o reserva en términos que no se ajustan a la preceptiva legal, conforme a la cual, y según lo ha resuelto la jurisprudencia administrativa de esta Contraloría General -dictámenes Ns. 42.779 de 2000, 35.421 de 2003, y 9.206 y 14.807, ambos de 2004, entre otros-, los sumarios administrativos están sujetos al principio de publicidad una vez afinados. Esta irregularidad se presenta, entre otras, en las resoluciones exentas $\mathrm{N}^{\circ}$ s. 2.475 de 2002 , de la Tesorería General de la República; 995 de 2002, del Servicio Médico Legal; 415 de 2002, de la Dirección de Presupuestos; 2.807 de 2002, de la Caja de Previsión de la Defensa Nacional, y 3 de 2003, de la Subsecretaría de Marina.

También a título ejemplar, en la mencionada resolución de la Caja de Previsión de la Defensa Nacional, se determinan como reservadas las declaraciones de intereses de los ejecutivos de la institución, en circunstancias que por expresa disposición del artículo 59 de la ley $\mathrm{N}^{\circ} 18.575$, las mismas son públicas.

A su vez, en diversas resoluciones se fijan materias sujetas a secreto o reserva en términos de tal amplitud que no resulta admisible entenderlas amparadas por la regulación legal y reglamentaria que debe servirles de fundamento.

Ello ocurre, por ejemplo, con las citadas resoluciones de la Tesorería General de la República en lo que se refiere a "todos los documentos que respalden egresos cualquiera que sea su naturaleza, origen y destino", y "contratos de cualquier naturaleza suscritos por el Servicio"; de la Dirección de Presupuestos en cuanto a "decisiones y conclusiones respecto de estudios y análisis de temas de cualquier naturaleza"; de la Caja de Previsión de la Defensa Nacional respecto de las "Actas de las Sesiones" del Consejo de la entidad y sus antecedentes, y de la Subsecretaría de Marina, al fijar que "como regla general, tendrá el carácter de reservado todo trámite previo al pronunciamiento del respectivo acto administrativo".

Finalmente, debe observarse que en distintas resoluciones no se advierte el fundamento preciso para declarar secretos o reservados determinados documentos, como acontece, entre otras, en la antes individualizada resolución de la Subsecretaría de Marina respecto, por ejem- 
plo, del decreto supremo de nombramiento del Comandante en Jefe de la Armada, y de los antecedentes que se indican relativos a concesiones marítimas.

\section{CONCLUSIONES}

Atendido lo precedentemente expuesto, se adopten las medidas tendientes a que todas las reparticiones que han dictado resoluciones invocando el artículo $9^{\circ}$ del reglamento sobre secreto o reserva de los actos y documentos de la Administración del Estado, las reexaminen a la brevedad de acuerdo con los criterios indicados en el cuerpo de este pronunciamiento y, en los casos en que corresponda, las modifiquen en términos que se ajusten a la normativa que les sirve de fundamento.

Transcríbase a la Comisión Nacional del Medio Ambiente, a la Tesorería General de la República, al Servicio Médico Legal, a la Dirección de Presupuestos, a la Caja de Previsión de la Defensa Nacional, a la Subsecretaría de Marina, a la División de Auditoría Administrativa, a la División de Vivienda y Urbanismo y Obras Públicas y Transportes, y al interesado.

Dios guarde a US.,

GUSTAVO SCIOLLA AVENDAÑO

Contralor General de la República 